\title{
Performance Evaluation of a Generator Differential Protection Function for a Numerical Relay
}

\author{
Kim Hung Le \\ The University of Danang - University of Science and \\ Technology \\ Da Nang, Vietnam \\ lekimhung@dut.udn.vn
}

\author{
Phan Huan Vu \\ Central Power Corporation - Central Electrical Testing \\ Company Limited \\ Da Nang, Vietnam \\ vuphanhuan@gmail.com
}

\begin{abstract}
This paper describes the advantages and disadvantages of a generator differential protection relay system which uses double slope characteristics of Areva P343, ABB REG670, SEL300G and GE G60. A Buon Tua Srah Hydropower Plant in Vietnam was selected as an example for the relay setting calculations of these characteristics. The performance of the introduced relay model was tested at various fault conditions in Matlab/Simulink. The results apply to the problems of solving the performance of the relay accurately and with reliable differential protection against internal faults, and keeping the generator stable on all external faults and in normal conditions. The simulation simplifies the process of selecting the relay and protection system. This can improve the quality of the protection system design early, thereby reducing the number of errors found later in the operation.
\end{abstract}

Keywords-generator; differential protection function; slope 1; slope 2; Matlab/Simulink

\section{INTRODUCTION}

The synchronous generator is the most important element of a power system. Generator faults are considered serious since they may cause severe and costly damages to insulation, windings, and stator core. The large short circuit currents cause large current forces, which can damage other components in the power plant, such as the turbine and the generator-turbine shaft, or even initiate explosion and fire. In addition, if the generator is tripped in connection to an external short circuit, it can give an increased risk of power system collapse. To limit the damages in connection to a stator winding short circuits and abnormal operating conditions, generators need to be protected as much as possible by a proper protection system [1]. Nowadays, there are a variety of numerical different protective relays on the market which include many functions in one unit, and provide metering, communication, and generator protection. These protective relays help us to simplify the protection implementation in circuit design and setting calculations. Although there is quite an agreement among protection engineers as to what constitutes the necessary protection and how to provide it, there are still many differences of opinion in certain areas. As protection system complexity increases with IEDs connected to the hydropower plant, the evaluation of effective protection relay becomes a need for well-designed algorithms that can allow or deny arranged trip of generator, field circuit, and neutral breakers (if used) through a lockout relay based on decisions, to enable fault isolation. Among them, generator differential protection function $(\mathrm{F} 87 \mathrm{G})$ is one of the most critical protection applications. It is mainly employed for the protection of stator windings of generator against earth faults and phase-to-phase faults. It is also of great importance that the F87G does not trip for external faults when the large fault current is fed from the generator. The need to evaluate $\mathrm{F} 87 \mathrm{G}$ with individual different characteristics has been well known to generator protection engineers. The techniques, methods and practices to provide this coordination are well established but scattered in various textbooks, papers, and in manufacturer's user manuals [2].

Author in [1] evaluated the performance of the F87G of the SEL $300 \mathrm{G}$ generator protection relay which was employed to protect the particular low resistance grounded 555MVA generator represented in the real-time simulation model of the RSCAD generic software. Authors in [3] considered the F87G and simulated this function using Simulink. Authors in [4] described the effects of damages in secondary circuits and the influence on disoperation of differential protection Micom P633 of the unit generator-transformer in Simulink. Authors in [5] conducted performance evaluation of the F87G by using a dynamic model of ATP/EMTP software for a large steam turbine synchronous generator. Authors in [6] used ATPEMTP package to simulate and generate fault data which were processed in Matlab to implement relay logic for detecting internal faults in the stator windings of F87G. Authors in [7] used an ANFIS algorithm in Simulink to design a F87G. The technical manuals of Schneider P343, ABB REG670, SEL300G and GE G60 relay protections are in $[9,11,14,15]$ respectively. The works on detailed settings guidance $[10,12$, $13,16]$ allow protective relaying engineers to have a clear understanding of which methods are available on every relay protection, what input parameters are required for each method and the expected results of each. In practice, the worst condition of unbalanced secondary currents is realized when the current transformer (CT) in the faulted circuit is completely saturated and none of the other CTs suffers a reduction in ratio. It is a universal differential protection problem for an unwanted trip of the generator [8]. Besides, there is a possibility that 
someone with unauthorized access might infiltrate the relay and reconfigure incorrect settings instructing it to release a false trip signal without the existence of a fault. When these types of misoperation risks go undetected, it is very easy for operators to mistakenly believe that their relay protection is secure. Hence, the question that operators need to ask is: "How confident am I that my relay protection is reliable and secure?". Therefore, the purpose of this paper is to provide a single document that can be used to calculate relay setting parameters with multi-vendors, to answer the most frequently asked questions about F87G considering the Buon Tua Srah Hydropower Plant in Vietnam. In addition, a Matlab/Simulink model to check four generator differential characteristics to the plant will be checked while simulating fault cases. It will equip the reader with the knowledge to choose the most suitable vendor for his or her project.

\section{GENERATOR DIFFERENTIAL PROTECTION FUNCTION}

This section shows how an $\mathrm{F} 87 \mathrm{G}$ characteristic is constructed and how it works. Selection rules for setting parameters are discussed. As an example, Figure 1 illustrates the schematic diagram for the implementation of the main generator protection of a Buon Tua Srah Hydropower Plant. Line side CTs and neutral side CTs are both ends of the stator winding which are wye-connected. The $\mathrm{F} 87 \mathrm{G}$ relies on measurements of the currents of the protected generator in order to calculate differential and biased currents which are then utilized to make tripping decisions. On low-impedance grounded machines, this scheme can detect phase-to-phase, phase-to-ground, and three-phase faults. Equations (1) and (2) show the mathematical definition of the differential and biased currents, respectively, which are employed by various vendors such as Schneider, ABB, SEL, and GE.

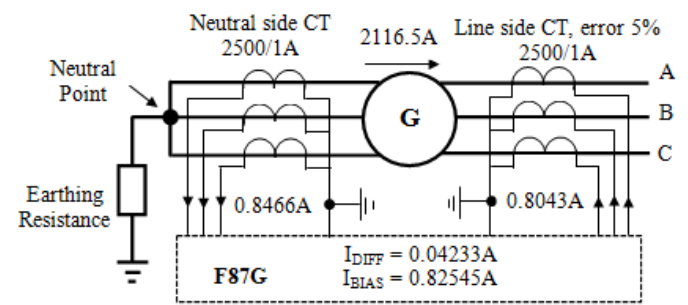

Fig. 1. Differential protection relay connection with a generator.

$$
\text { The differential current: } I_{D I F F}=\left|\bar{I}_{1}+\bar{I}_{2}\right|
$$

The biased current: $I_{B I A S}=\frac{\left|\bar{I}_{1}\right|+\left|\bar{I}_{2}\right|}{2}$

Based on these values of $I_{B I A S}$ and of $I_{D I F F}$, the trip/restrain characteristics are applied in the vendors of protection relay which has a three-step shape (two slopes and one pickup level) as in Figure 2. The differential current pickup setting $\left(I_{S 1}, I_{d m i n}\right.$, 87OP, Pickup) should avoid the maximum unbalance current under normal load condition which is mainly caused by CT error, the normal current error $\left(K_{C T E R R}\right)$ must be less than $5 \%$ the operating current for the 5P20 type CT, and we should multiply by a reliable coefficient $K_{R E L}$ that is normally equal to 1.5. This setting can be set as low as $5 \%$ of the rated generator current, to provide protection for as much of the winding as possible [10].

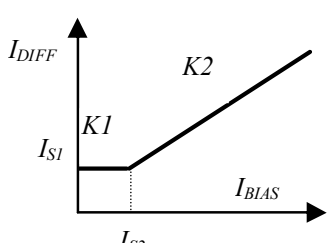

(a). Areva P343

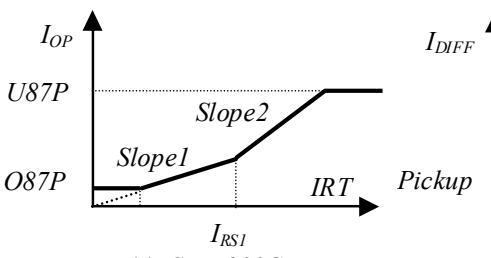

(c). SEL $300 \mathrm{G}$

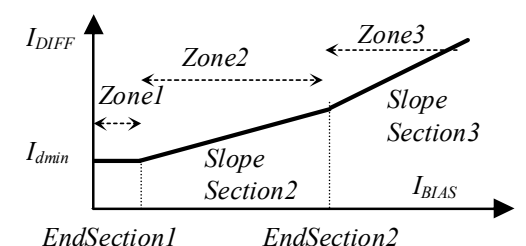

(b). ABB REG670

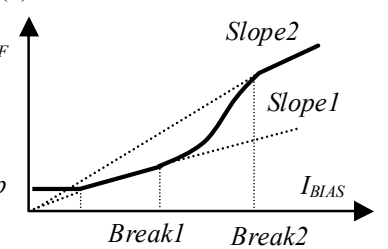

(d). GE G60
Fig. 2. Differential protection characteristics

Slope1 setting (K1, SlopeSection2, SLP1, and Slope1) is set to ensure sensitivity to internal faults at normal operating current levels. The criterion for setting this slope is to allow maximum expected $\mathrm{CT}$ mismatch error when operating at maximum permitted current. In this case, it combines the $K_{C T_{-} E R R}$. The relay pickup accuracy $\left(K_{R E L A Y \_E R R}\right)$ can be obtained from the instruction manual of the relay, and an operating margin $\left(K_{M A R G I N}\right)$ of $5 \%$ is typically provided in order to increase the security of the differential protection scheme [13]. The purpose of the Slope2 setting (K2, SlopeSection3, SLP2, Slope2) is to increase the security of the differential protection scheme during heavy through-fault conditions. It can result in severe saturation of a CT. When a CT saturates, it can no longer trustworthy reproduce the primary current with a scale factor on the secondary side of the CT. As a result, a very high differential current may be obtained under this fault condition. The Slope 2 setting is typically set higher than the Slope1 setting. Relay setting calculation is an important task for a power plant before operating. The parameter in this calculation is used for the setting of the relay protection equipment of the power plant. Choosing the slope of a differential relay has been more art than science. Manufacturer's guidelines tend to be qualitative or empirical in nature. They are based on the manufacturer's experience and knowledge of his/her design [9], as shown in the above F87G using trip/restrain characteristics. We can calculate detailed adjustable settings by using the generator parameters as in Table I [10].

\section{A. Schneider P343 [11, 12]}

IsI is calculated to avoid maximum unbalance under normal load and the $K 1$ should be $0 \%$ to assure the sensitive under normal operating current.

$$
I_{S 1}=\frac{K_{R E L} \times K_{E R R . C T} \times I_{G . N}}{C T}=\frac{1.5 \times(2 \times 0.05) \times 2116.5}{2500}=0.127,
$$

so, $0.2 \mathrm{~A}$ is proper. 
The Is 2 should be the same with CT rating current or generator's $120 \%$ nominal current. CT rating current is $2500 \mathrm{~A}$, so $I s 2=2500 \mathrm{~A}$, the secondary value is $I s 2=1 \mathrm{~A}$. The $K 2$ is normally to avoid external max unbalance current under max throughout fault near protection zone. This max unbalance current can be calculated according to:

$$
I_{U n b . M a x}=K_{R E L} \times K_{A P} \times K_{C C} \times K_{E R R . C T} \times I^{(3)}{ }_{\text {Max }}
$$

where the external three phase short circuit current is: $I_{\text {Max }}^{(3)}=\frac{I_{G . N}}{X_{d}^{\prime \prime} \times C T}=\frac{2116.5}{0.2093 \times 2500}=4.045$. The CT type factor $K_{C C}$ should be 0.5 when same type CT for each side, or be 1 when different type CT for each side. In this paper, we select 0.5 . The non-periodic factor is $K_{A P}=1.5 \sim 2.0$. In this paper, we select 2.0. So: $I_{\text {Unb.Max }}=1.5 \times 2 \times 0.5 \times 0.1 \times 4.045=0.6068$.

According to the equation:

$$
K 2=\frac{I_{U n b . M a x}-I_{S 1}}{I_{M a x}^{(3)}-I_{S 2}}=\frac{0.6068-0.2}{4.045-1}=0.1336 \quad \text {, we } \quad \text { suggest }
$$

selecting $K 2=0.2$. The $\mathrm{F} 87 \mathrm{G}$ operates when $I_{D I F F}$ exceeds $I s I$ and the percentage of $I_{B I A S}$, defined by a slope setting $(K 1, K 2)$. It can be calculated using the following:

$$
\begin{aligned}
& I_{D I F F}>K_{1} \times I_{B I A S}+I_{S 1} \text { where } I_{B I A S} \leq I_{S 2} \\
& I_{D I F F}>K_{2} \times I_{B I A S}-\left(K_{2}-K_{1}\right) \times I_{S 2}+I_{S 1} \text { where } I_{B I A S}>I_{S 1}
\end{aligned}
$$

\begin{tabular}{|c|c|}
\hline Parameters & Values \\
\hline Rated capacity & $50.6 \mathrm{MVA}$ \\
\hline Normal Current $I_{G . \mathrm{N}}$ & $2116.5 \mathrm{~A}$ \\
\hline Rated Voltage & $13.8 \mathrm{kV}$ \\
\hline Frequency & $50 \mathrm{~Hz}$ \\
\hline $\begin{array}{c}\text { PT ratio of the terminal of the } \\
\text { generator }\end{array}$ & $\frac{13.8}{\sqrt{3}} / \frac{0.11}{\sqrt{3}} / \frac{0.11}{\sqrt{3}} / 0.11$ \\
\hline Line CT ratio & $2500 / 1$ \\
\hline Neutral CT ratio & $2500 / 1$ \\
\hline Rated current secondly & $0.8466 \mathrm{~A}$ \\
\hline Synchronous reactance $X d$ & $99.28 \%$ \\
\hline Transient reactance $X^{\prime} d$ & $28.27 \%$ \\
\hline Sub Transient reactance $X^{\prime \prime} d$ & $20.93 \%$ \\
\hline Synchronous reactance $X q$ & $62.88 \%$ \\
\hline Negative reactance $X 2$ & $23.60 \%$ \\
\hline Static negative current $I_{2 \infty}$ & $250 \mathrm{~A}$ \\
\hline Transient negative current $\boldsymbol{I}_{2 t}^{2}$ & $40 \mathrm{~s}$ \\
\hline$K_{R E L A Y_{-} E R R}$ & $\begin{array}{l}\text { SEL300G is } 2 \% \text {, G60 is } 1 \% \text {, } \\
\mathrm{P} 434 \text { is } 5 \% \text {, and REG670 is } 2 \%\end{array}$ \\
\hline
\end{tabular}

TABLE I. PARAMETERS OF BUON TUA SRAH HYDROPOWER PLANT

\section{B. ABB REG670 [9, 10]}

The pick-up value $\left(I_{d m i n}\right)$ is:

$$
I_{d \min }=\frac{K_{R E L} \times K_{E R R . C T} \times I_{G . N}}{C T}=\frac{1.5 \times(2 \times 0.05) \times 2116.5}{2500}=0.127
$$

We set $\mathrm{I}_{\mathrm{dmin}}=0.2 \mathrm{I}_{\mathrm{G} . \mathrm{N}}$.

In Section1, the risk of false differential current is very low. This is the case, EndSection 1 is set to experience value:

$$
\text { End Section } 1=\frac{0.5 \times I_{G . N}}{C T}=\frac{0.5 \times 2116.5}{2500}=0.4233
$$

A SlopeSection 2 is proposed to be set to $30 \%$. Breakpoint 2 set to experience value:

$$
\text { End } \operatorname{Sec} \text { tion } 2=\frac{3 \times I_{G . N}}{C T}=\frac{3 \times 2116.5}{2500}=2.5398
$$

SlopeSection $3=80 \%$. It is supposed to cope with false differential currents related to current transformer saturation. The F87G operates when $I_{D I F F}$ exceeds a threshold $I_{d m i n}$ and a percentage of $I_{B I A S}$ :

$$
\begin{aligned}
& I_{\text {DIFF }}>\left[I_{\text {dmin }}+\text { SlopeSection } 2 \times\left(I_{\text {BIAS }}-\text { EndSection } 1\right)\right] \\
& \text { when Endsection } 1 \leq I_{\text {BIAS }} \leq \text { EndSection } 2 \\
& I_{\text {DIFF }}>\left[I_{\text {dmin }}+\text { SlopeSection } 2 \times(\text { EndSection } 2-\text { EndSection } 1)\right. \\
& \left.+ \text { SlopeSection } 3 \times\left(I_{\text {BIAS }}-\text { EndSection } 2\right)\right] \\
& \text { when } I_{\text {BIAS }} \geq \text { EndSection } 2
\end{aligned}
$$

\section{SEL300G [13, 14]}

The Slopel setting can be calculated as:

$$
S L P 1=2 \times I_{C T_{-} E R R}+K_{R E L A Y_{-} E R R}+K_{\text {MARGIN }}
$$

$S L P 1=2 \times 5 \%+2 \%+5 \%=17 \%$, so $20 \%$ is proper. O $87 \mathrm{P}$ setting is calculated using the guidance shown in equation: $O 87 P=0.5 * S L P I=0.1$

The SLP2 setting is fixed to $100 \%$, the turning point between Slopel and Slope2 defined by the value IRS1 is fixed to 3.0 per unit. The purpose of the Unrestrained Differential Element Pickup Setting (U87P) is to detect the very high differential current that clearly indicates a fault inside the differential protection zone. The $U 87 P$ setting is set to 10 per unit as recommended by the relay manufacturer. The criteria for internal and external faults can be seen from the differential characteristic and are described below:

$$
\begin{aligned}
& I_{D I F F}>087 P \text { where } I_{B I A S} \leq 087 P / S P L 1 \\
& I_{D I F F}>I_{B I A S} \times S L P 1 \text { when } O 87 P / S P L 1<I_{B I A S}<I_{R S 1} \\
& I_{D I F F}>I_{B I A S} \times S L P 2+(S L P 1-S L P 2) \times I_{B I A S} \text { when } I_{B I A S} \geq I_{R S 1}
\end{aligned}
$$

\section{GE Multilin $G 60[15,16]$}

$$
\text { Pickup }=\frac{K_{R E L} \times I_{\text {er.n }} \times I_{G . N}}{C T}=\frac{1.5 \times 0.02 \times 2116.5}{2500}=0.025398 \text {, so }
$$

$0.1 \mathrm{~A}$ is proper. Slopel is set at $15 \%$ starting from 0.04 (RC). The Breakl setting should greater than the maximum overload expected for the machine:

$$
\text { Break } 1=\frac{1.05 \times I_{G . N}}{C T}=\frac{1.05 \times 2116.5}{2500}=0.88893 \text {, so it is set at } 1.2
$$

Slope 2 is set at $80 \%$.

The Break2 setting is set at 3 or 4 . It provides security from misoperation for maximum fault and resulting maximum CT error condition. The criteria for internal and external faults can be seen from the differential characteristic and are described below: 
$I_{\text {DIFF }}>$ Pickup where $I_{\text {BIAS }} \leq$ Pickup / Slope 1

$I_{\text {DIFF }}>$ Slope $1 \times I_{B I A S}$ when Pickup / Slope $1<I_{B I A S}<$ Break 1

$I_{\text {DIFF }} \geq C_{0}+C_{1} \times I_{B I A S}+C_{2} \times I_{B I A S}^{2}+C_{3} \times I_{B I A S}^{3}$

when Break $1<I_{B I A S}<$ Break2, where:

$C_{0}=\frac{2 \times(\text { Slope } 1-\text { Slope } 2) \times \text { Break } 1^{2} \times \text { Break } 2^{2}}{(\text { Break } 1-\text { Break } 2)^{3}}$

$C_{1}=\frac{\text { Slope } 2 \times \text { Break } 1 \times\left(\text { Break } 1^{2}+\text { Break } 1 \times \text { Break } 2+4 \times \text { Break } 2^{2}\right)}{(\text { Break } 1-\text { Break } 2)^{3}}$

Slope $1 \times$ Break $2 \times\left(4 \times\right.$ Break $^{2}+$ Break $1 \times$ Break $2+$ Break $\left.2^{2}\right)$ $(\text { Break } 1-\text { Break } 2)^{3}$

$C_{2}=\frac{2 \times(\text { Slope } 1-\text { Slope } 2) \times\left(\text { Break } 1^{2}+\text { Break } 1 \times \text { Break } 2+\text { Break } 2^{2}\right)}{(\text { Break } 1-\text { Break } 2)^{3}}$

$C_{3}=\frac{(\text { Slope } 2-\text { Slope } 1) \times(\text { Break } 1+\text { Break } 2)}{(\text { Break } 1-\text { Break } 2)^{3}}$

and $I_{D I F F}>$ Slope $2 \times I_{B I A S}$ when $I_{B I A S} \geq$ Break 2

All setting parameter results are calculated based on the best manufacturer practices that are adjusted to compensate for $\mathrm{CT}$ ratio error mismatch and CT response via a dual slope characteristic typically as shown in Figure 7.

Review: The numerical algorithm of the $\mathrm{F} 87 \mathrm{G}$ is very similar to motor differential protection. It is also principally simpler than that of the power transformer differential protection. No phase shifts, and no transformation ratios, typical for power transformers, must be numerically allowed for. The suggested protection for instantaneous and sensitive protection for generator internal faults is presented in [17]. The variable slope percentage differential relay is a widely used form of differential relaying for generator protection. In this type of relay, the percentage slope characteristic may vary from about $10 \%$ at low values of through current up to $100 \%$ or more at high values of through current. A P434 is more sensitive than another relay with $K I=0 \%$ during light internal faults and relatively low sensitivity $(K 2=20 \%)$ during heavy external faults.

\section{POWER SYSTEM UNDER STUDY}

Matlab/Simulink tool is useful for the basic understanding of power system protection, particularly for new engineers. It helps them to model the F87G system behavior under normal and fault conditions. In this section, the $\mathrm{F} 87 \mathrm{G}$ performance is tested on the $13.8 \mathrm{kV}, 50.6 \mathrm{MVA}$ synchronous generator, connected with $220 \mathrm{kV}$ through a 51MVA, D11Yn step-up transformer as shown in Figure 3.

\section{A. The Generator}

The generator is represented by its impedance and an $\mathrm{AC}$ source, required for the system supply. It is located at the point where one side can easily be grounded. A resistor of $0.5 \Omega$, which exists in the actual grounded generator neutral, is not represented. This assumption does not have a significant influence on the study.

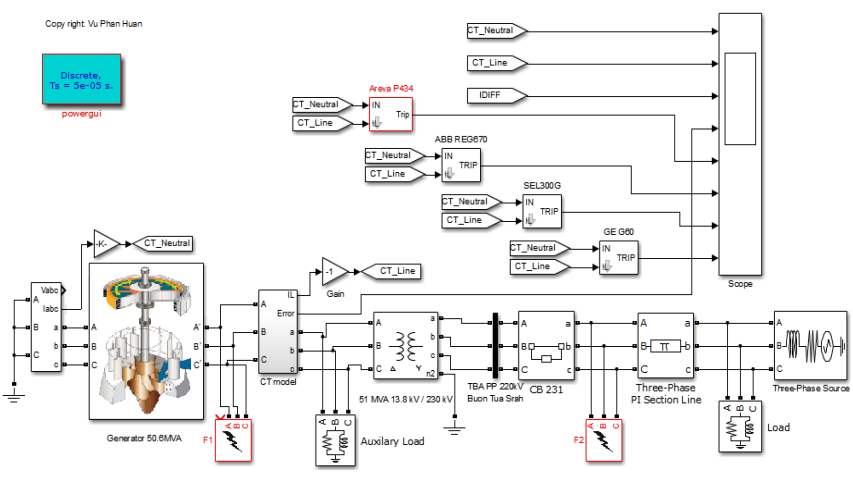

Fig. 3. Power system model

\section{B. Current Transformer Models}

Current phasors at both ends of stator windings are 2500/1A 5P20 30VA which are performed the current transformer excitation test, measured the $\mathrm{CT}$ winding resistance and CT current-ratio automatically by The Vanguard EZCT2000 test set in Central Electrical Testing Company Limited. All of the EZCT's test leads can be connected to the CT output terminals, eliminating the need for lead switching during testing. Test voltage output is automatically raised and lowered by the EZCT without any operator intervention. Once the test is completed, test results can be printed and excitation curves can be plotted on the built-in 4.5 -inch wide thermal printer as in Figure 4.
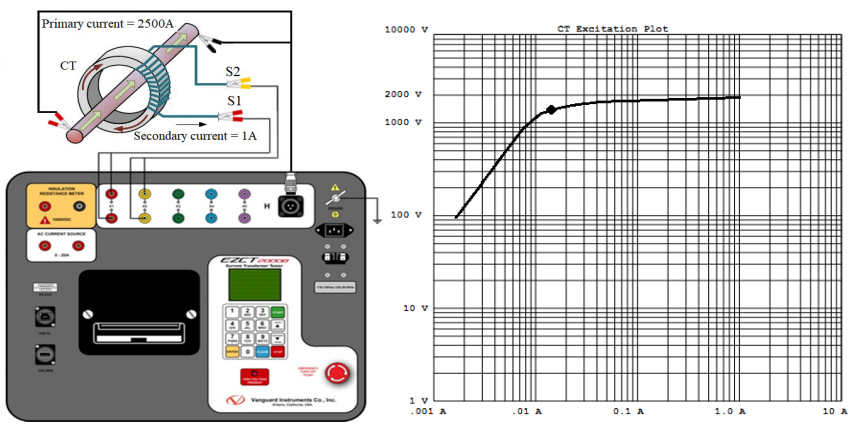

Fig. 4. V-I curve of CT 2500/1 A

Knee Type IEC 10/50 standard [18]: $V p k=1401.44 \mathrm{~V}$, $I p k=0.0124 \mathrm{~A}$, CT ratio: $2485.885 / 1 \mathrm{~A}$, Error: $0.5646 \%$, Ex $V=99.6 \mathrm{~V}$, Ex $I=0.02 \mathrm{~A}$, Phase angle: 0.120 , CT Pole: In Phase, and Winding Res: $13.94 \Omega$.

The proposed mathematical current transformer model is shown in Figure 5 and is based on the CT Saturation Theory and Calculator presented by the IEEE Power System Relaying and Control Committee (PSRC) and the practical testing results of CT by Vanguard EZCT-2000 test set above (See [19] for more details). 


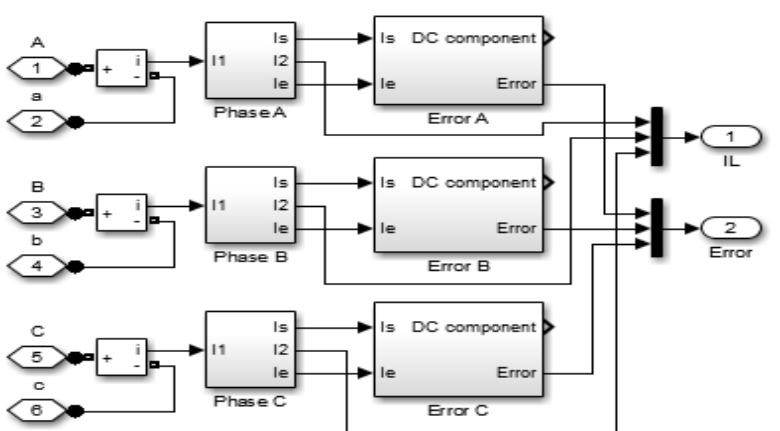

Fig. 5. A mathematical current transformer model

\section{Different Protection Relay Model}

By performing the essential computations given in Section II, we got the four models of F87G relay (P343, REG670, SEL300G, G60) which are connected on CT's secondary side at both ends of the generator (IL, IN). After that, these signals were calculated using recursive discrete Fourier transform algorithm. These are combined with setting parameters sending to S-function block. This block has been developed for detecting generator stator winding internal faults. If the output from the S-function block is equal to zero, this means that there is no fault in the stator winding of the generator, otherwise, the stator winding of the generator has a fault. The inside Simulink model of F87G block is shown in Figure 6.

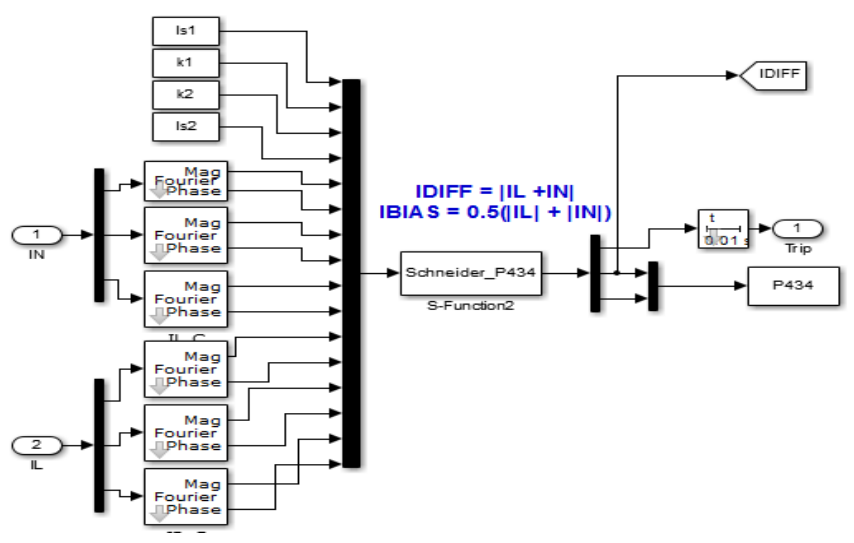

Fig. 6. Differential protection relay P434 block

\section{Three Phase Fault Block}

Three phase fault block F1 and F2 generate fault types and fault resistance varying from $1 \Omega$ to $35 \Omega$ which are inside the protected zone, and out of the protected zone, respectively.

\section{Simulation RESUlts}

After the building of the proposed model has been completed, it is ready to analyze the operation of $\mathrm{F} 87 \mathrm{G}$ applied under three cases below. In the first case, the normal condition shows the phase current waveforms captured at both terminal $I_{N}=I_{L}=2200 \mathrm{~A}$, CT Error $\approx 0 \%, I_{D I F F} \approx 0 \mathrm{~A}$ and all relays have not generated trip signal. The trajectory of the operating point can be seen by the relay lied the restrain zone (Figure 7).
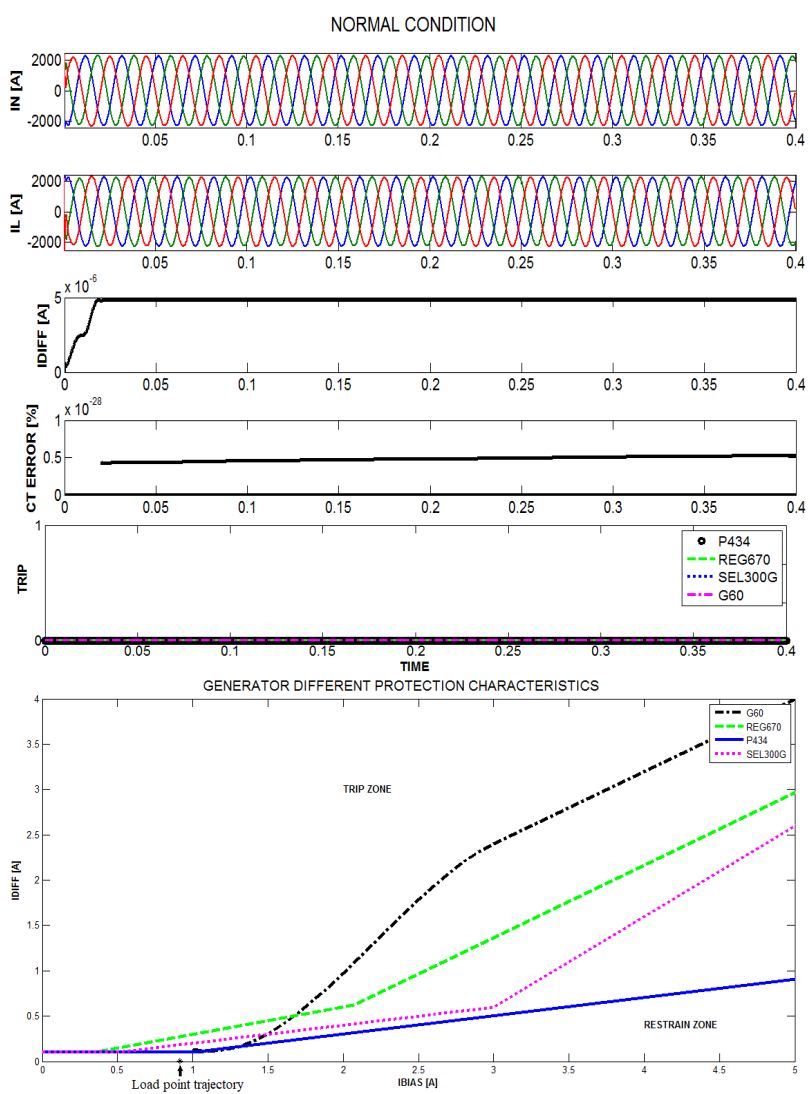

Fig. 7. Current waves, CT error, trip signals and trajectory of operating point for normal condition

In the second case, the internal fault occurs at $0.16 \mathrm{~s}$ on the terminal of phase 'ABG' stator winding as shown in Figure 8. The phase currents captured at both terminals $I_{N}=2 \mathrm{kA}, I_{L}=1 \mathrm{kA}$ and remain in the same phase, CT Error $\approx 0 \%, I_{D I F F} \approx 8 \mathrm{~A}$. According to change in current waveforms during the fault, the trajectory of the operating point moves quickly into trip zone, which results in a tripping at 0.178s (REG670), 0.1832s (SEL300G and G60), 0.1835s (P434). In the third case, a threephase fault occurs at $0.1 \mathrm{~s}$ on the terminal of a synchronous generator that is external to the stator winding. If the CTs have no error, then currents at both ends of stator windings remain in the same value and opposite phase, and $I_{D I F F} \approx 0 \mathrm{~A}$. Unfortunately, during fault conditions as shown in Figure 9, CTs do not always perform ideally, since core saturation may cause a breakdown of a ratio $\left(I_{N}=20 \mathrm{kA}, I_{L}=1.8 \mathrm{kA}\right)$. Such core saturation usually from $0.13 \mathrm{~s}$ to $0.15 \mathrm{~s}$ is the result of a DC transient in the primary fault current, total burden impedance $Z_{B}=150 \Omega$ and may be aggravated by the residual flux left in the core by a previous fault. The trajectory of the operating point moves into the trip zone of P434, SEL300G, and REG670. After that, it comes back to the restrain zone at $0.23 \mathrm{~s}$. Therefore, in order to provide additional security against maloperations during this event, the relay incorporates saturation detection logic. When saturation is detected, the 
element will make an additional check on the angle between the neutral and line current. If this angle indicates an internal fault then tripping is permitted. In this case, the generator does not trip because the differential relay does not a response to the fault since the fault happens out of the protected zone.
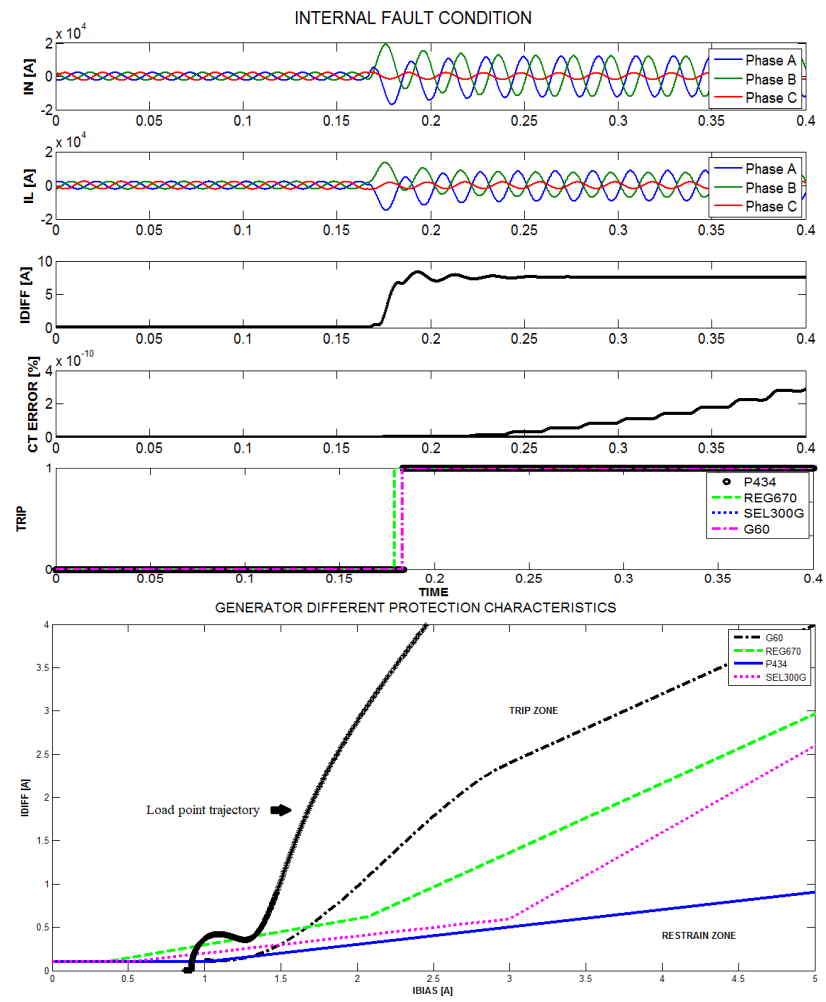

Fig. 8. Current waves, CT error, trip sinals and and trajectory of operating point for internal fault condition (ABG fault)

Review: The simulation results show that under the no-fault condition and external fault then the relay does not trip; under a fault condition, the trip signal is taken. In another way the characteristic results are very sensitive to internal faults and insensitive to CT error currents during severe external faults.

\section{CONCLUSIONS}

In order to verify the deployed generator protection scheme is working as designed after field installation, this paper is discussed with a Buon Tua Srah Hydropower plant example. The paper provides calculation on appropriate a pickup threshold, slope and breakpoint settings for an F87G function available from today's modern multifunctional generator protection IEDs such as P434, REG670, SEL300G, and G60. It also presents important aspects of generator protection system analyzing at different conditions which are simulated on a synchronous machine stator winding in Matlab/Simulink. This software shows the two CTs' current waves, and the different and restraint current trajectories on the relay characteristics. It tells the user how far the different locus intrudes into the trip zone. According to the obtained results, it has been shown that the IEDs operate safe and reliable.
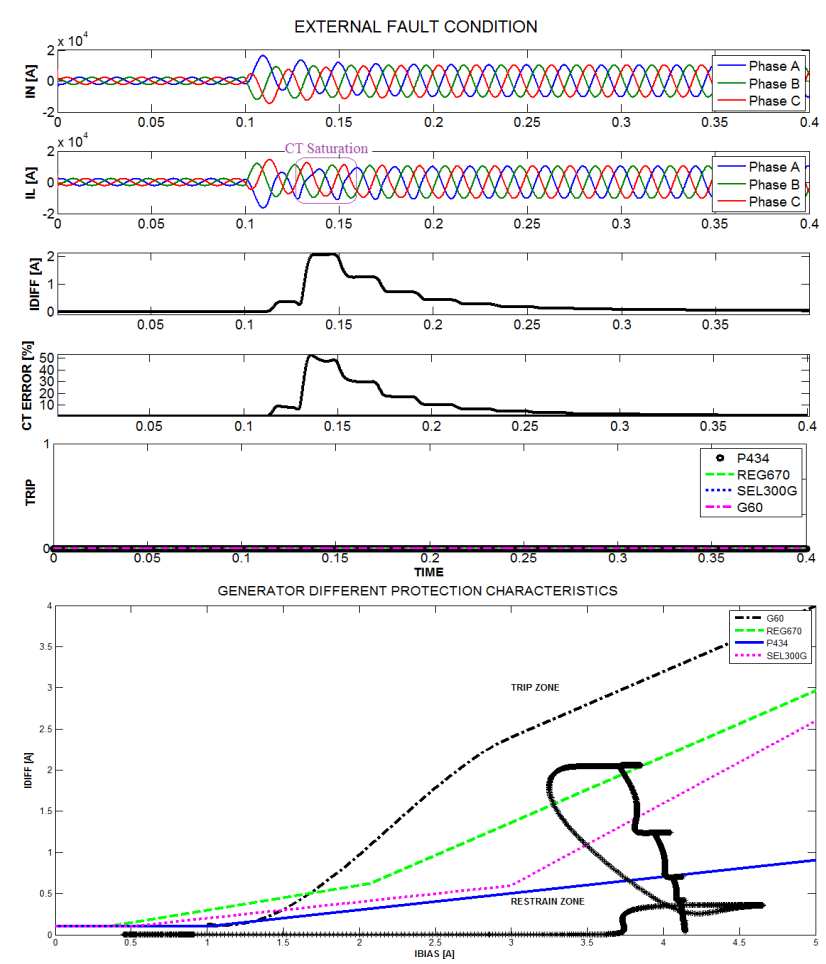

Fig. 9. Current waves, CT error, trip sinals and and trajectory of operating point for external fault condition (ABC fault)

\section{ACKNOWLEDGMENT}

The authors would like to thank the Central Electrical Testing Company Limited, Vietnam for allowing the use of the test record of current transformer, setting the calculations of Hydropower Plants used in this study.

\section{REFERENCES}

[1] Y. T. Huang, Investigating the Performance of Generator Protection Relays Using a Real-Time Simulator, MSc Thesis, University of KwaZulu-Natal, 2013

[2] D. Reimert, Protection Relaying for Power Generation Systems, Taylor \& Francis Group, 2006

[3] M. V. Sudhakar, L. K. Sahu, "Simulation of Generator Protection using Matlab", IEEE International Conference on Smart Technologies and Management for Computing, Communication, Controls, Energy and Materials, Chennai, India, August 2-4, 2017

[4] K. Kadriu, G. Kabashi, L. Ahma, "Misoperation of the Differential Protection During the Dynamic Processes of Faults in the Secondary Protection Circuit. Differential Protection Modeling with MATLAB Software and Fault Simulation", 5th WSEAS International Conference on Power Systems and Electromagnetic Compatibility, Corfu, Greece, August 23-25, 2005

[5] W. Yousef, M. A. Elsadd, A. Y. Abdelaziz, M. A. Badr, "Performance evaluation of generator-transformer unit overall differential protection in large power plant", International Journal on Power Engineering and Energy, Vol. 9, No. 3, pp. 869-877, 2018

[6] N. W. Kinhekar, S. Daingade, A. Kinhekar, "Current Differential Protection of Alternator Stator Winding", International Conference on Power Systems Transients, Kyoto, Japan, June 3-6, 2009

[7] R. Mohemmed, A. Cakir, "Modeling and simulation of differential relay for stator winding generator protection by using ANFIS algorithm", International Journal of Scientific \& Engineering Research, Vol. 7, No. 12 , pp. $1668-1673,2016$ 
[8] IEEE, C37.102 Guide for AC Generator Protection, IEEE, 2006

[9] ABB, Generator Protection REG670 Application Manual, ABB, 2012

[10] ABB Engineering (Shanghai) Ltd, \#1, \#2 G-T UNIT Protection Setting Calculations for Buon Tua Srah Hydro Power Plant, ABB Engineering, 2009

[11] Schneider Electric, MiCOM P343 Generator Protection Relay-Technical Manual, Schneider Electric, 2011

[12] Ecidi-Alstom Consortium, Cscs System Protection Parameter Calculation, Vnss4-C3-9-001 /A, Ecidi-Alstom Consortium, 2010

[13] XJ Electricity Co., Generator Relay Protection Setting Calculation Instruction, XJ Electricity Co., 2010

[14] SEL, SEL-300G Multifunction Generator Relay Instruction Manual, SEL, 2018

[15] GE Digital Energy, G60 Generator Protection System-Instruction Manual, GE Digital Energy, 2015

[16] GE Grid Automation, Application Book-CT Requirements for GE Multilin Relays, GE Grid Automation, 2016

[17] I. Brncic, Z. Gajic, S. Roxenborg, Adaptive Differential Protection for Generators and Shunt Reactors, ABB Power Technologies AB, 2007

[18] Central Electrical Testing Company Limited, "The test record of current transformer 2500/1A, 5P20 30VA, 04/17/2014", 2014

[19] K. H. Le, P. H. Vu, "Testing and Evaluation of Factors Affecting the Current Transformer Saturation", Journal of Science and Technology, Thai Nguyen University, Vol. 189, No. 13, pp. 129-134, 2018 (in Vietnamese) 